\title{
Influence of Injection Conditions on Field Tracer Experiments
}

\author{
by Serge Brouyère ${ }^{1,2,5}$, Guy Carabin ${ }^{1,3}$, and Alain Dassargues ${ }^{1,4}$
}

\begin{abstract}
Calibration of ground water transport models is often performed using results of field tracer experiments. However, little attention is usually paid to the influence, on resulting breakthrough curves, of injection conditions and well-aquifer interactions, more particularly of the influence of the possible trapping of the tracer in the injection wellbore. Recently, a new mathematical and numerical approach has been developed to model injection conditions and well-aquifer interactions in a very accurate way. Using an analytical solution derived from this model, a detailed analysis is made of the evolution of the tracer input function in the aquifer. By varying injection conditions from one simulation to another, synthetic breakthrough curves are generated with the SUFT3D ground water flow and transport finite-element simulator. These tests show clearly that the shape of the breakthrough curves can be dramatically affected by injection conditions. Using generated breakthrough curves as "actual" field results, a calibration of hydrodispersive parameters is performed, neglecting the influence of injection conditions. This shows that neglecting the influence of actual injection conditions can lead to (1) errors on fitted parameters and (2) misleading identification of the active transport processes. Conclusions and guidelines are drawn in terms of proposed methodologies for better controlling the tracer injection in the field, in order to minimize risk of misinterpretation of results.
\end{abstract}

\section{Introduction}

The reliability of ground water transport models depends strongly on accurate identification of hydrodispersive processes and quantification of the corresponding parameters. Calibration of these models is often performed using results of field tracer experiments. The breakthrough curve obtained by measuring tracer concentrations in water samples collected at an observation or pumping well can be considered as the response, at that location, of the aquifer system to tracer injection at another point (injection well). As shown by Brouyère (2003), tracer injection is a complex process, and it is

\footnotetext{
${ }^{1}$ Hydrogeology Group, Department of Georesources, Geotechnologies and Building Materials, University of Liège, Building B52/3, 4000 Liège, Belgium.

${ }^{2}$ Also at Aquapôle ULg, Belgium.

${ }^{3}$ Now at NUMECA International, CFD Group, Brussels, Belgium.

${ }^{4}$ Also at the Department of Geology and Geography, KULeuven, Belgium.

${ }^{5}$ Corresponding author: (32) 43-66-23-77; fax (32) 43-6695-20; serge.brouyere@ulg.ac.be

Received September 15, 2003; accepted September 11, 2004 Copyright (c) 2005 National Ground Water Association.
}

thus important that it be carefully controlled in the field and simulated realistically in models for analyzing tracer breakthrough curves.

Guvanasen and Guvanasen (1987) studied the influence of an injection performed with a finite volume of tracer followed by an intense water flush. They represent the tracer injection as a radially diverging piston flow (no dispersion) around the injection well, without considering wellbore mixing. This produces an initial ring-shaped distribution of the tracer around the injection well, which is then transported toward the pumping well by advection and hydrodynamic dispersion. At the extreme, they showed that this way of simulating tracer injection can lead to the occurrence of modeled double-peaked breakthrough curves. However, in practice, this remains a relatively uncommon tracer injection methodology, similar to the dipole flow tracer experiment. Novakowski (1992a, 1992b) studied mathematically and experimentally the influence of boundary conditions on tracer displacements in one-dimensional columns. He discussed the influence of wellbore mixing on the results and directly generalized his conclusions to the case of field tracer tests. However, he did not address the additional complexities that might 
be present during tracer injection in wells. Moench (1989, 1996), Welty and Gelhar (1994), Zlotnik and Logan (1996), and Chen et al. (2003) developed analytical solutions for modeling tracer tests performed in various flow conditions that deal with mixing in the injection borehole. As an application of their models, they showed that, for large wellbore mixing effects, a spreading of the breakthrough curve and a reduction in peak concentration can be expected. However, their theoretical developments relied on the assumption that the tracer is diluted into an infinitesimal volume of water, injected without disturbing the ground water velocity distribution around the well. In practice, the volume of tracer is not infinitesimal. Furthermore, even if the subject is briefly discussed, the influence of injection conditions on tracer test results is actually not the central topic of their developments, and there are no clear recommendations and guidelines concerning the way to minimize any interpretation bias in relation with tracer injection or, at least, to control that problem in the field.

In fact, in the relatively abundant literature on field tracer experiments, one can find virtually no consideration and information on the way tracers are injected and how the experimenters manage to control the evolution of the tracer injection. Except for the SUFT3D code (Brouyère 2003), existing ground water flow and transport simulators, even the most common and widespread codes such as Modflow/MT3D, RT3D, FEFLOW, or Femwater, propose only "basic" source/sink terms as tools for modeling tracer injection. This indicates clearly that few experimenters and modelers are really aware of the problems they can encounter if they oversimplify the representation of the injection when modeling field tracer experiments.

In the next sections, the numerical approach proposed by Brouyère (2003) to model tracer injection accurately is used to determine how and to what extent the tracer injection can influence the shape of the breakthrough curve and its interpretation. Based on water and tracer mass balance equations integrated over the volume of water in the well, this physical approach allows for finite volumes of tracer fluid and water flush. It accommodates tracer mixing and trapping in the wellbore, local distortion of the flow field around the well and possible tracer back-migration into the well. The model was validated by showing its ability to reproduce concentration evolutions monitored in a well during field tracer experiments, considering various injection conditions. This approach thus makes it possible to model, in an accurate way, tracer injection as it is actually performed in the field.

In a first step, using an analytical solution derived from the injection model proposed by Brouyère (2003), a detailed analysis of the evolution of the tracer input function in the aquifer is performed. It is a function of the tracer injection profile (the way it is injected) and wellaquifer interactions (the way it is transferred from the well into the surrounding aquifer). This discussion allows for a better identification and understanding of factors that actually govern the influence of injection conditions on tracer test results. In a second step, in order to identify the kind and importance of errors that may affect tracer test results, a synthetic radially converging flow tracer experiment is modeled using the finite-element ground water flow and transport simulator SUFT3D (Carabin and Dassargues 1999; Brouyère 2001), in which the injection model was coded (Brouyère 2003). Different breakthrough curves are simulated, by varying the injection conditions (tracer volume, well-aquifer interaction parameters) while keeping all other conditions constant. These results can be considered as representative of actual field conditions: they will be called "field breakthrough curves." Modeling injection with a "classical" source term, as it is most often done by modelers, breakthrough curves fitted to the so-called field breakthrough curves are obtained by adapting the values of hydrodispersive parameters in the model. This analysis shows that neglecting the influence of injection conditions leads to identification of incorrect hydrodispersive processes affecting the fate of solutes in the aquifer and to estimation of inaccurate hydrodispersive parameters. Finally, based on these observations, general conclusions and guidelines are drawn in terms of methodologies proposed for better controlling tracer injection in order to minimize the risk of misinterpretation of the results.

\section{Tracer Input Function}

The tracer breakthrough curve can be expressed as a function $Y(t)$ given by the convolution product:

$$
Y(t)=\int_{0}^{\infty} F_{\mathrm{aq}}(t-\tau) X_{\mathrm{aq}}(\tau) d \tau=X_{\mathrm{aq}}(t) * F_{\mathrm{aq}}(t)
$$

where $X_{\mathrm{aq}}(t)$ is the tracer input function in the aquifer, and $F_{\text {aq }}(t)$ is the aquifer transfer function between injection and sampling points.

The transfer function $F_{\text {aq }}(t)$ is the aquifer impulse response corresponding to the instantaneous release in the aquifer of a unit mass of tracer at the injection point, $X_{\text {aq }}(t)=\delta_{\text {aq }}(t)$, where $\delta_{\text {aq }}(t)$ represents a Dirac-type input function at initial time.

This conceptual representation of the tracer experiment is depicted in Figure 1a. Through the impulse response $F_{\text {aq }}(t)$, the breakthrough curve $Y(t)$ depends on the hydrodynamic and hydrodispersive properties of the aquifer, on regional and local ground water flow conditions, and on the scale of the experiment. The breakthrough curve $Y(t)$ also depends on the tracer input function $X_{\mathrm{aq}}(t)$, and thus on injection conditions.

Classically, the mass of tracer $M_{\text {inj }}(\mathrm{M})$ is diluted into a volume of water $V_{\mathrm{inj}}\left(\mathrm{L}^{3}\right)$, at a concentration $C_{\mathrm{inj}}$ $\left(\mathrm{M} \mathrm{L}^{-3}\right)$. The tracer fluid is injected during a period $T_{\mathrm{inj}}$ (T), at an injection rate $Q_{\text {inj }}\left(\mathrm{L}^{3} \mathrm{~T}^{-1}\right)$. When the tracer injection is completed, a more or less important quantity of tracer remains in the injection well, from where it is progressively released in the aquifer, with the help of the flow rate $Q_{\mathrm{t}}\left(\mathrm{L}^{3} \mathrm{~T}^{-1}\right)$ that is intercepted by the injection well screens due to motion of ground water in the aquifer (hereafter called the transit flow rate). When modeled, the tracer input function is often approximated by a simple source term, represented mathematically by a step function of duration $T_{\mathrm{inj}}$, directly applied to the aquifer 


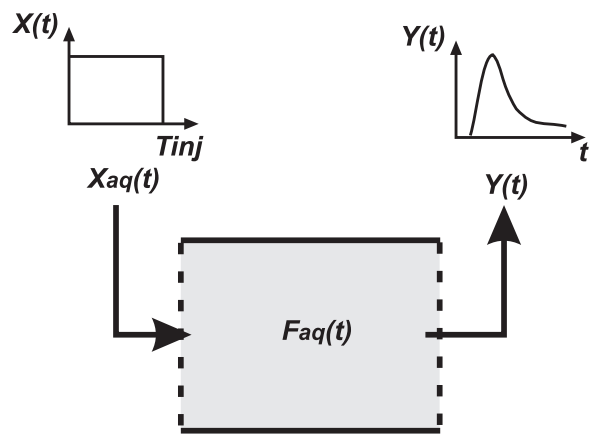

(a)

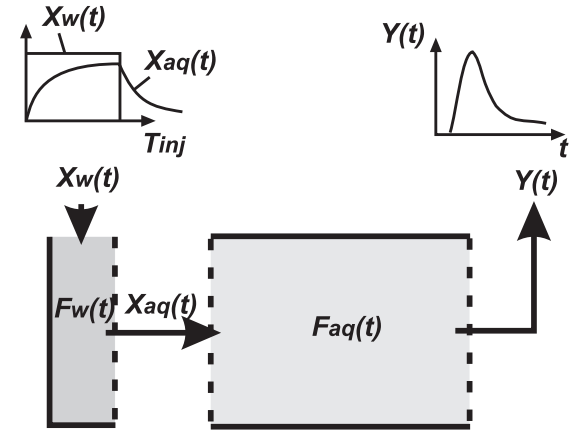

(b)

Figure 1. (a) Classical and (b) more accurate conceptual representation of the tracer experiment.

medium. In reality, this formulation expresses only the tracer injection into the well, which is denoted $X_{\mathrm{w}}(t)$. The actual tracer input function in the aquifer, $X_{\mathrm{aq}}(t)$, results from the convolution between $X_{\mathrm{w}}(t)$ and the well-aquifer transfer function $F_{\mathrm{w}}(t)$ :

$$
X_{\mathrm{aq}}(t)=X_{w}(t) * F_{w}(t)
$$

With this representation of $X_{\text {aq }}(t)$, the measured breakthrough curve results from the following more complex convolution product:

$$
Y(t)=F_{\mathrm{aq}}(t) * X_{\mathrm{aq}}(t)=F_{\mathrm{aq}}(t) *\left(F_{w}(t) * X_{w}(t)\right)
$$

This more accurate conceptual representation of the tracer experiment is depicted in Figure 1b. To model accurately tracer injection into a well, Brouyère (2003) proposed a mathematical approach based on the tracer mass balance equation integrated over the volume of water in the injection well (Figure 2):

$$
\pi r_{\mathrm{w}}^{2}\left(C_{\mathrm{w}} \frac{\partial h_{\mathrm{w}}}{\partial t}+h_{\mathrm{w}} \frac{\mathrm{d} C_{\mathrm{w}}}{\mathrm{d} t}\right)=Q_{\mathrm{in}} C_{\mathrm{in}}+Q_{t}^{\text {in }} C_{t}-Q_{\mathrm{out}} C_{\mathrm{w}}
$$

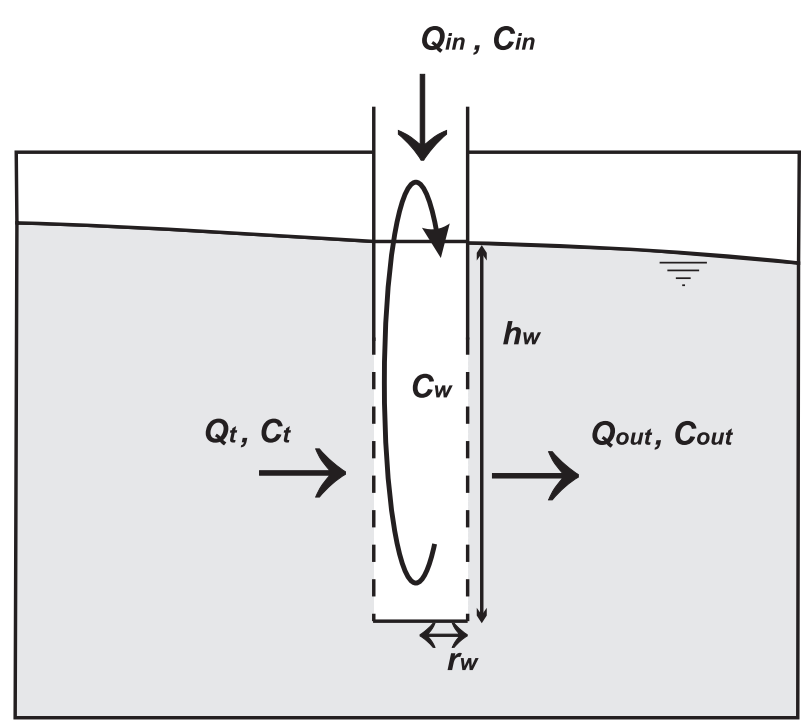

Figure 2. Schematic representation of the well-aquifer system and exchanged fluxes. Mixing within the wellbore causes uniform concentration.
In Equation 4, the left-hand-side term represents the storage of tracer in the wellbore, the right-hand side representing the different tracer exchange terms between the well and its environment. The terms $h_{\mathrm{w}}(\mathrm{L})$ and $r_{\mathrm{w}}(\mathrm{L})$ represent the length of the water column in the wellbore and the radius of the injection well, respectively. $C_{\mathrm{w}}, C_{\mathrm{in}}$, and $C_{\mathrm{t}}$ are variables accounting for concentrations (M $\mathrm{L}^{-3}$ ) in, respectively, the well, the water injected at a rate $Q_{\text {in }}\left(\mathrm{L}^{3} \mathrm{~T}^{-1}\right)$, and flow rate $Q_{\mathrm{t}}^{\text {in }}\left(\mathrm{L}^{3} \mathrm{~T}^{-1}\right)$ intercepted by the well at the screen level (transit flow rate), due to pumping at the recovery well or, more generally, to natural motion of water in the aquifer. $Q_{\text {out }}\left(\mathrm{L}^{3} \mathrm{~T}^{-1}\right)$ is the flow rate that leaves the well through the screens, carrying tracer at concentration $C_{\mathrm{w}}$. The superscript "in" in the transit flow rate $Q_{\mathrm{t}}^{\text {in }}$ represents the fact that this term dynamically depends on the injection rate $Q_{\text {in }}$ (see Brouyère 2003 for details). The transit flow rate is maximum when the injection rate is null; it is progressively decreased as the injection rate is increased until it is canceled at some "critical injection rate." The relationship between $Q_{\mathrm{t}}{ }_{\mathrm{in}}$ and $Q_{\mathrm{in}}$ is derived from the potential theory of Bidaux and Tsang (1991), assuming that, locally, the different fluxes reach equilibrium almost instantaneously:

$Q_{t}^{\text {in }}=2 r_{w} e_{\text {scr }} \alpha_{w}\left|\underline{v}_{D}\right| \sin \left(\arccos Q_{\mathrm{in}}^{*}\right)-\frac{Q_{\mathrm{in}}}{2 \pi}\left(2 \arccos Q_{\mathrm{in}}^{*}\right)$

where $Q_{\mathrm{in}}^{*}=Q_{\mathrm{in}} / Q_{\mathrm{cr}} ; Q_{\mathrm{cr}}=2 \pi r_{w} e_{\mathrm{scr}} \alpha_{w}\left|\underline{v}_{D}\right|$ is the critical injection rate such that the transit flow rate $Q_{\mathrm{t}}^{\text {in }}$ is zero; $e_{\text {scr }}$ is the screen length (L), $\alpha_{\mathrm{w}}$ is a nondimensional coefficient, and $\left|\underline{v}_{D}\right|$ is the mean Darcy flux $\left(\mathrm{L} \mathrm{T}^{-1}\right)$ that prevails in the aquifer close to the injection well. In Equation 5 , the screens are assumed to be fully saturated with water (i.e., $e_{\text {scr }}$ is assumed to be constant and independent of $h_{\mathrm{w}}$ ).

Theoretically, the coefficient $\alpha_{\mathrm{w}}$ is a correction factor that in homogeneous conditions reflects the possible distortion of the flow field around the injection well. In that case, $\alpha_{w}$ is expressed as the ratio between the actual water flow rate $Q_{\mathrm{t}}{ }^{0}$ crossing, in natural flow conditions $\left(Q_{\text {in }}=0\right)$, the well section orthogonal to the main flow direction and the theoretical flow rate $Q_{\text {theor }}$ that would cross the same section if the well was not present (Drost et al. 1968; Hall 1996). In perfectly radially converging 
flow conditions, the Darcy velocity close to the injection well should be $\left|\underline{v}_{D}\right|=Q_{W} / 2 \pi d e_{\mathrm{aq}}$, where $Q_{\mathrm{W}}$ is the extracted flow rate $\left(\mathrm{L}^{3} \mathrm{~T}^{-1}\right)$ at the pumping (recovery) well, $d$ is the distance (L) between the injection well and the pumping well, and $e_{\mathrm{aq}}$ is the aquifer thickness (L). In that case, the theoretical flow rate $Q_{\text {theor }}$ is equal to the Darcy velocity $\left|v_{D}\right|$ multiplied by the screen section $S_{\mathrm{scr}}=$ $2 r_{w} e_{\text {scr }}$ orthogonal to the main flow direction. In this strongly simplified case, the coefficient $\alpha_{\mathrm{w}}$ may vary between 0 and 4 (Havely et al. 1967; Drost et al. 1968; Bidaux and Tsang 1991). Here, the coefficient $\alpha_{w}$ is considered in a more general sense as a lumping correction factor that accounts for any discrepancy between the theoretical flow rate $Q_{\text {theor }}$ and actual flow rate $Q_{\mathrm{t}}{ }^{0}$ that crosses the screens of the injection well. This difference can result from the aquifer heterogeneity or from the existence of a vertical hydraulic gradient along the injection well axis. It can also reflect the possible influence of the water circulation performed to homogenize the tracer concentration and to monitor the evolution of concentration in the injection well. From that point of view, $\alpha_{w}$ may vary over a larger range. Based on measured concentration evolutions monitored in the field, Brouyère (2003) found values larger than 10 for this coefficient. The coefficient $\alpha_{w}$ can be computed analytically provided that detailed information is available for the hydraulic properties and geometry of the well screens, gravel pack, and the aquifer medium close to the well (Havely et al. 1967; Drost et al. 1968; Bidaux and Tsang 1991). Practically, it can be estimated by fitting the computed concentration evolution to the concentration evolution monitored in the injection well (Brouyère 2003).

Table 1 summarizes the values taken by the variables appearing in Equations 4 and 5 for the different steps of the injection operations. During each step, it is assumed that the concentration terms and the flow rate terms remain constant. However, they can change from one step to the other so that the injection can be described most accurately. For the sake of clarity and generality, the following discussion is based on a nondimensional analytical solution derived from Equation 4.

\section{Analytical Solution}

In order to derive a useful closed-form expression, simplifying assumptions are made. First, the concentration $C_{\mathrm{t}}$ in the transit flow rate is neglected. Second, the

\begin{tabular}{|c|c|c|c|c|c|}
\hline \multicolumn{6}{|c|}{$\begin{array}{c}\text { Table } 1 \\
\text { Values Taken by the Variables Appearing in } \\
\text { Equations } 4 \text { and } 5 \text { for the Different Steps } \\
\text { of the Injection Process }\end{array}$} \\
\hline & \multicolumn{5}{|c|}{ Variable } \\
\hline & $C_{\mathrm{in}}$ & $V_{\text {in }}$ & $Q_{\text {in }}$ & $Q_{\mathrm{t}}^{\mathrm{in}}$ & $Q_{\text {out }}$ \\
\hline $\begin{array}{l}\text { During tracer injection } \\
\text { After tracer injection }\end{array}$ & $\begin{array}{l}C_{\mathrm{inj}} \\
0\end{array}$ & $\begin{array}{l}V_{\mathrm{inj}} \\
0\end{array}$ & $\begin{array}{l}Q_{\text {inj }} \\
0\end{array}$ & $\begin{array}{l}Q_{\mathrm{t}}^{\mathrm{inj}} \\
Q_{\mathrm{t}}^{0}\end{array}$ & $\underset{Q_{\mathrm{t}}{ }^{0}}{Q_{\mathrm{inj}}}+Q_{\mathrm{t}}^{\mathrm{inj}}$ \\
\hline
\end{tabular}

volume of water $V_{w}=\pi r_{w}^{2} h_{w}$ in the injection well is assumed to be constant. These simplifications are not restrictive. Most often, since the injection rate is relatively low and the hydraulic conductivity of the tested aquifer is generally high, the variation in ground water level in the injection well can be neglected. When this is not the case, a rise in ground water level in the injection well would just produce a temporary enhanced storage of the tracer in the wellbore followed by its delayed release in the aquifer when the injection is completed. This would just introduce some delay in the tracer entry function in the aquifer.

With these assumptions, Equation 4 becomes:

$$
\pi r_{\mathrm{w}}^{2} h_{\mathrm{w}} \frac{\mathrm{d} C_{\mathrm{w}}}{d t}=V_{\mathrm{w}} \frac{\mathrm{d} C_{\mathrm{w}}}{\mathrm{d} t}=Q_{\mathrm{in}} C_{\mathrm{in}}-Q_{\mathrm{out}} C_{\mathrm{w}}
$$

with $Q_{\text {out }}=Q_{\text {in }}+Q_{t}^{\text {in }}$.

Considering the initial condition $C_{\mathrm{w}}\left(t=t_{0}\right)=C_{0}$, Equation 6 can be solved analytically, resulting in the following expression to compute the concentration evolution in the injection well:

$$
C_{w}(t)=\frac{Q_{\mathrm{in}} C_{\mathrm{in}}-\left(Q_{\mathrm{in}} C_{\mathrm{in}}-Q_{\mathrm{out}} C_{0}\right) \exp \left(-\frac{Q_{\mathrm{out}}}{V_{w}}\left(t-t_{0}\right)\right)}{Q_{\text {out }}}
$$

Provided that adequate values are defined for the concentration and flow rate terms (Table 1), Equation 7 can be used to compute the concentration evolution for any step of the tracer injection. Equation 7 extends the classical point dilution method (e.g., Havely et al. 1967; Drost et al. 1968; Hall 1996) to the case of finite volumes of tracer fluid and finite duration of tracer injection. Because the point dilution technique relies on strong assumptions (instantaneous injection and mixing of tracer diluted into an infinitesimal volume of water), Equation 7 is a major improvement since it generalizes the former technique to experimental conditions that are more realistic and more easy to perform in the field (Brouyère 2001).

A more general form of Equation 7 can be obtained using nondimensional variables. Concentration terms are normalized according to the concentration in the tracer fluid $C_{\mathrm{inj}}$, volumes are normalized according to the volume of water in the wellbore $V_{\mathrm{w}}$, flow rate terms are normalized according to the critical injection rate $Q_{\mathrm{cr}}$, and time is normalized as follows: $t^{*}=\left(t-t_{0}\right) / T_{\mathrm{w}}$, where $T_{\mathrm{w}}$ is the time needed to replace the water in the wellbore at the critical injection rate $\left(T_{\mathrm{w}}=V_{\mathrm{w}} / Q_{\mathrm{cr}}\right)$. The values taken by the nondimensional variables for the different steps of the tracer injection are summarized in Table 2. The nondimensional form of Equation 7 can be written as follows:

$$
C_{\mathrm{w}}^{*}\left(t^{*}\right)=\frac{Q_{\mathrm{in}}^{*} C_{\mathrm{in}}^{*}-\left(Q_{\mathrm{in}}^{*} C_{\mathrm{in}}^{*}-Q_{\mathrm{out}}^{*} C_{0}^{*}\right) \exp \left(-Q_{\mathrm{out}}^{*} t^{*}\right)}{Q_{\mathrm{out}}^{*}}
$$

A dimensionless expression can also be obtained for the cumulative mass $M_{\text {out }}^{*}$ that has left the well after a dimensionless time $t^{*}$ : 


\begin{tabular}{|l} 
Values Taken by the Nondimensional Variables Appearing in Equations 8 and 9 for the \\
Different Steps of the Injection Process \\
\cline { 2 - 6 } \\
\cline { 2 - 6 } \\
\cline { 2 - 6 }
\end{tabular}

$$
\begin{aligned}
M_{\mathrm{out}}^{*}\left(t^{*}\right) & =\frac{M_{\mathrm{out}}\left(t^{*}\right)}{M_{\mathrm{inj}}}=\int_{0}^{t^{*}} \frac{C_{\mathrm{w}}^{*}\left(t^{\prime \prime}\right) Q_{\mathrm{out}}^{*}\left(t^{\prime \prime}\right)}{V_{\mathrm{inj}}^{*}} \mathrm{~d} t^{\prime \prime} \\
& =\frac{t^{*}}{t_{\mathrm{in}}^{*}} C_{\mathrm{in}}^{*}+\frac{\left(Q_{\mathrm{in}}^{*} C_{\mathrm{in}}^{*}-Q_{\mathrm{out}}^{*} C_{0}^{*}\right)\left(\exp \left(-Q_{\mathrm{out}}^{*} t^{*}\right)-1\right)}{V_{\mathrm{inj}}^{*} Q_{\mathrm{out}}^{*}}
\end{aligned}
$$

In Equation 9, the first term of the right-hand side expresses a linear evolution with time of the quantity of tracer in the aquifer. This is the mathematical expression of the classical source term used to model tracer injection in most analytical solutions or numerical models. The second term is the correction provided by the injection model in order to take into account the fact that the tracer is not immediately transferred from the well to the aquifer, because part of it is temporarily trapped in the wellbore.

\section{Possible Injection Profiles}

It is assumed that the tracer is diluted in a volume $V_{\mathrm{inj}}^{*}=V_{\mathrm{inj}} / V_{\mathrm{w}}$ that is injected during a period $t_{\mathrm{inj}}^{*}=T_{\mathrm{inj}} / T_{\mathrm{w}}$. After injection, the transit flow rate crossing the well screens in natural flow conditions contributes to flushing the remaining quantity of tracer out of the injection well. Plotting Equation 9 in a nondimensional diagram (Figure 3) allows one to identify the different possible injection scenarios.

A tracer injection modeled with a constant source term of finite duration $t_{\text {inj }}{ }^{*}$ (step function) plots as the straight line (a) in Figure 3, connecting point $(0,0)$ because no tracer is present in the aquifer at initial time, to point $\left(t_{\mathrm{inj}}{ }^{*}, 1\right)$, meaning that, as soon as the injection operation is completed, the whole quantity of tracer is considered to be in the aquifer. The actual tracer mass evolution (i.e., as computed with Equation 9) follows the

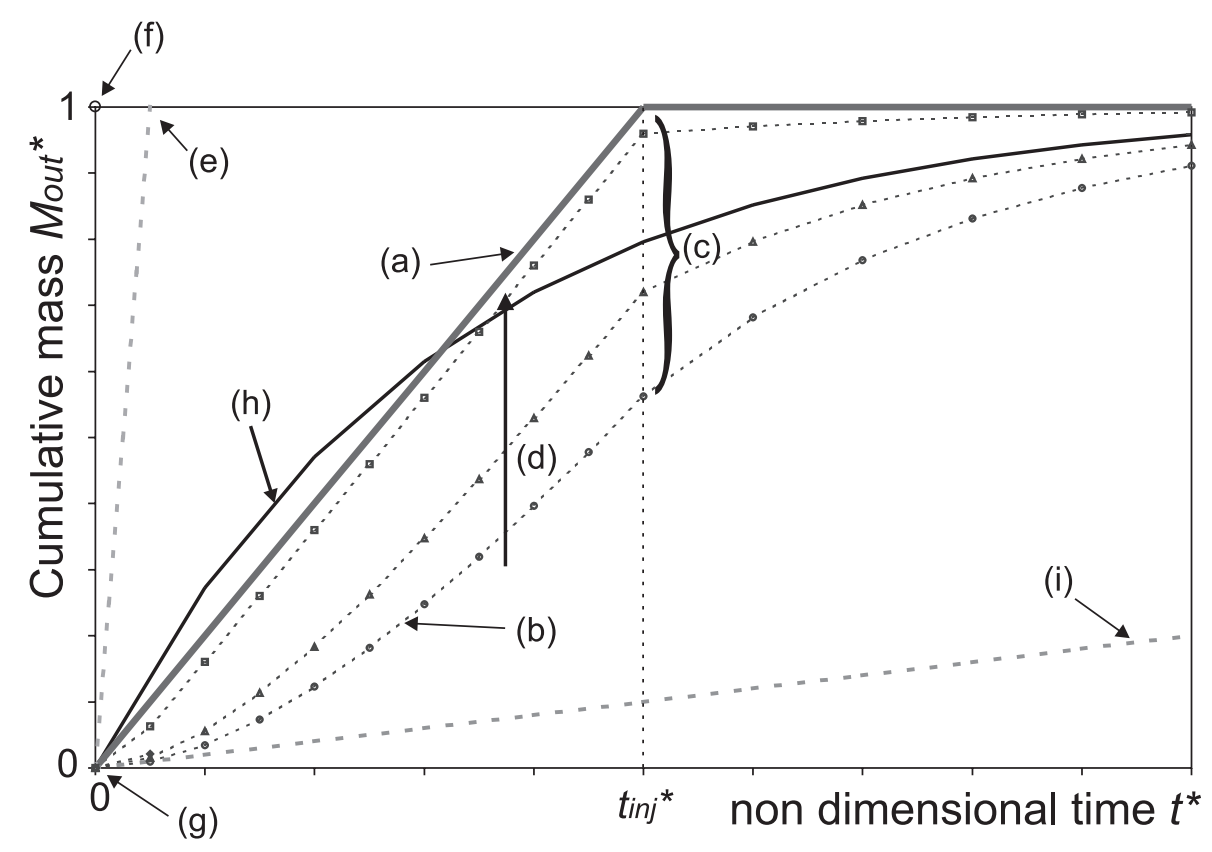

Figure 3. Description of possible injection profiles depending on tracer injection conditions: (a) constant source term of finite duration (step function); (b) actual injection profile obtained with a mixing factor $V_{\mathrm{inj}}^{*}=0.5$; (c) quantity of tracer that remains temporally stored in the wellbore at the end of the tracer injection; (d) for increasing values of the tracer fluid volume (i.e., $V_{\mathrm{inj}}^{*}=0.5,2.5$, and 25, respectively), the actual evolution of tracer mass evolution in the aquifer becomes closer to the theoretical step function; (e) tracer injection performed with a very large volume of tracer in a very short time, close to (f) the theoretical instantaneous tracer injection in the aquifer (Dirac-type $\delta_{\mathrm{aq}}$ ); $(\mathrm{g})$ tracer injection performed with an infinitesimal tracer fluid volume, in a very short time, close to (h) the theoretical instantaneous tracer injection in the well (Dirac-type $\left.\delta_{w}\right)$; and (i) very long duration tracer injection with a flat, slowly increasing evolution of mass in the aquifer. 
more complex path (b) in Figure 3. At any time, the difference between the source-type evolution and the actual evolution represents the quantity of tracer that is temporarily stored in the well (c, in Figure 3 ). For a given injection duration $t_{\mathrm{inj}}{ }^{*}$, the higher the tracer fluid volume $t_{\mathrm{inj}}{ }^{*}$, the closer the actual tracer mass evolution is to the theoretical step function (d, in Figure 3). After injection is completed, the remaining quantity of tracer in the well is progressively released in the aquifer at a rate governed by the transit flow rate $\left(Q_{t}^{0 *}=Q_{t}^{0} / Q_{\mathrm{cr}}\right)$ crossing the well screens. An injection performed over a very short time, and with a large volume of tracer fluid (e, in Figure 3), is often approximated by an instantaneous tracer input function (Dirac-type $\delta_{\text {aq }}$ ) in the aquifer (f, in Figure 3). In contrast, when the tracer fluid volume is very small compared to the volume of water in the well, it can be assumed that the whole quantity of tracer is still present in the well at the end of the injection ( $\mathrm{g}$, in Figure 3), and that further tracer evolution depends only on the intensity of the transit flow rate crossing the well screens. This can be seen as a Dirac-type $\left(\delta_{\mathrm{w}}\right)$ tracer injection in the well (h, in Figure 3). Finally, a very long tracer fluid injection would follow a flat, slowly increasing evolution of mass in the aquifer (i, in Figure 3).

As a result, the mixing factor $V_{\mathrm{inj}}^{*}$ appears to play a crucial role as it partitions the quantity of tracer between a fraction that is "directly" injected in the aquifer and another fraction remaining for a longer period in the well. This period depends on the transit flow rate $Q_{t}^{0 *}$, which drives the evolution of the tracer input function after injection. This flow rate can be expressed as the product of the flow rate that would prevail in the aquifer in the absence of the well and the coefficient $\alpha_{\mathrm{w}}$ expressing the distortion induced locally by the well on the flow field. The mixing factor $V_{\mathrm{inj}}{ }^{*}$, and the distortion coefficient $\alpha_{\mathrm{w}}$ will thus be varied in the numerical tests performed to evaluate the influence of well-aquifer interactions on tracer test results.

\section{How Can Injection Influence Tracer Test Results?}

The tracer experiment aims to identify the impulse response $F_{\text {aq }}(t)$ between two points in the aquifer. The resulting information is the tracer breakthrough curve $Y(t)$ at the observation point (the pumping well for a radially converging flow tracer test). According to Equation 1, these two functions are equal when the tracer injection in the aquifer can be considered as instantaneous, i.e., when $X_{\mathrm{aq}}(t)=\delta_{\mathrm{aq}}(t)$. Otherwise, the experiment is influenced by tracer injection conditions.

According to Equation 3, the tracer input function in the aquifer $X_{\mathrm{aq}}(t)$ may differ from the Dirac-type injection profile if the injection operation is not instantaneous, i.e., $X_{w}(t) \neq \delta(t)$, as well as if well-aquifer interactions have an important effect on the shape of the tracer input function in the aquifer, i.e., $F_{\mathrm{w}}(t) \neq \delta(t)$. This leads to the conclusion that two categories of numerical tests need to be performed. First, the influence of the tracer injection duration must be examined; second, the impact of well-aquifer interactions must be considered.

\section{Sensitivity of the Breakthrough Curve to Injection Conditions}

\section{Description of the Tests}

Injection duration and well-aquifer interactions simultaneously affect tracer behavior. However, for the sake of clarity, their respective influence is examined separately. The first category of numerical experiments aims to test the influence of the injection duration. Increasing durations are successively considered. The injection is modeled with a source term represented by a step function of duration $T_{\mathrm{inj}}$. For the tracer test configuration considered, this allows determination of the maximum injection duration for which the breakthrough curve $Y(t)$ can still be approximated as the aquifer impulse response $F_{\text {aq }}(t)$. This maximum duration will be further conventionally called the "maximum admissible injection duration" $T_{\mathrm{inj}}^{\max }$. The second category of numerical experiments involves evaluating the influence of well-aquifer interactions. The injection model coded in the SUFT3D (Brouyère 2003) is used, with an injection duration that is shorter than the maximum admissible injection duration $T_{\mathrm{inj}}{ }^{\max }$ (defined on the basis of the first set of numerical experiments). In both cases, the influence of injection conditions is examined by comparing the field breakthrough curves $Y(t)$ to the aquifer impulse response $F_{\text {aq }}(t)$.

The synthetic example consists of modeling a radially converging flow tracer experiment in a homogeneous, fully saturated aquifer, using the finite-element simulator SUFT3D. The discretized domain has dimensions of 640 by $640 \mathrm{~m}$, with a thickness of $e_{\mathrm{aq}}=8 \mathrm{~m}$, subdivided into four layers of finite elements. Horizontally, elements have sizes ranging from $0.5 \mathrm{~m}$ at the center of the domain to 16 $\mathrm{m}$ close to the external boundaries. Initial total heads are $10 \mathrm{~m}$ throughout the model domain (confined aquifer), and prescribed heads are imposed at all lateral boundaries. Hydrodynamic and hydrodispersive properties are summarized in Table 3. They reflect alluvial gravel deposits in which a multitracer experiment was performed (Brouyère 2001). The spatial and temporal discretizations were chosen in order to have a Peclet number equal to 0.25 and a Courant number less than unity. The recovery well, located at the center of the grid, has a radius of 10 $\mathrm{cm}$. It is screened along the entire $8 \mathrm{~m}$ aquifer thickness. Water is extracted from the aquifer at a constant pumping rate $Q_{\mathrm{p}}=50 \mathrm{~m}^{3} / \mathrm{h}$. An injection well is located at a distance $d=20 \mathrm{~m}$ away from the pumping well. It has a radius of $7.5 \mathrm{~cm}$, and it is also screened over the full aquifer thickness. Both wells are modeled with one-

\begin{tabular}{|ll|}
\hline \multicolumn{2}{|c|}{ Table 3 } \\
Hydrodynamic and Hydrodispersive Parameters \\
Considered for the Synthetic Test Case
\end{tabular}


dimensional elements, using the approach proposed by Brouyère (2003). For such an experimental configuration, the advective travel time $t_{\text {adv }}$ between the two wells, used as a comparative time, can be evaluated as follows:

$$
\begin{aligned}
T_{\mathrm{adv}} & =\frac{\pi d^{2} e_{\mathrm{aq}} \theta_{m}}{Q_{\mathrm{p}}}=\frac{\pi \times 20^{2} \times 8 \times 0.05}{(50 / 3600)} \\
& =36,191.15 \mathrm{~s} \approx 10 \mathrm{~h}
\end{aligned}
$$

\section{Influence of Experimental Injection Duration}

Breakthrough curves were generated for injection durations ranging from $600.0 \mathrm{~s}(10 \mathrm{~min})$ to $36,000.0 \mathrm{~s}$ $(10 \mathrm{~h})$. Figure 4 shows the generated breakthrough curves (symbols); it indicates that a duration of $1 \mathrm{~h}$ can be considered as the maximum admissible injection duration $T_{\mathrm{inj}} \max *$.

To evaluate how misinterpretations may occur when neglecting the injection duration, computed breakthrough curves are fit to the field breakthrough curves that depart from the aquifer impulse response. These computed breakthrough curves use an injection duration of $2700 \mathrm{~s}$ (less than the maximum admissible injection duration). Results are plotted in Figure 4 (lines). Apparent hydrodispersive parameters resulting from this calibration are presented in Table 4. It appears that neglecting the actual injection duration can lead to overestimation of effective porosity and underestimation of longitudinal dispersivity. However, Figure 4 shows that when the actual injection duration is very long (nearly the same order of magnitude as the advective travel time), it becomes very difficult to obtain a good fit for the whole breakthrough curve, particularly for the tracer first arrivals. This is explained by the necessity of underestimating the longitudinal dispersivity in order to fit the concentration peak amplitude.

\begin{tabular}{|lccc|}
\hline \multicolumn{5}{|c|}{ Table $\mathbf{4}$} \\
Fitted Parameters Obtained When Neglecting \\
Injection Duration \\
\hline $\boldsymbol{T}_{\mathbf{i n j}}(\mathbf{s})$ & $\boldsymbol{T}_{\mathbf{i n j}} / \boldsymbol{T}_{\text {adv }}$ & $\boldsymbol{\theta}_{\mathbf{m}}(-)$ & $\boldsymbol{\alpha}_{\mathbf{L}}(\mathbf{m})$ \\
\hline$\delta_{\text {aq }}$ & 0.0 & 0.050 & 2.00 \\
7200 & 0.2 & 0.051 & 1.83 \\
18,000 & 0.5 & 0.059 & 1.45 \\
36,000 & $\sim 1.0$ & 0.077 & 1.15 \\
\hline
\end{tabular}

\section{Influence of Well-Aquifer Inteactions}

As discussed previously, two key factors control the input function of the tracer in the aquifer: the mixing factor $V_{\mathrm{inj}}{ }^{*}$, and the transit flow rate $Q_{\mathrm{t}, 0}{ }^{*}$. When the mixing factor is high, as soon as the injection is completed, most of the tracer is already in the aquifer and the injection process cannot have any further influence on tracer test results. In contrast, if the mixing factor is low, the evolution of the experiment strongly depends on the transit flow rate crossing the well screens. If the latter is high, the well is quickly flushed. If it is low, a nonnegligible fraction of tracer may remain captured in the well for a long period, in which case the breakthrough curve shape can be strongly affected.

Using an injection duration of $2700 \mathrm{~s}$, which is shorter than the maximum admissible injection duration $T_{\mathrm{inj}}{ }^{\max }$, a total of 30 breakthrough curves are generated by varying the mixing factor $V_{\mathrm{inj}}{ }^{*}$ and the transit flow rate $Q_{\mathrm{t}, 0}{ }^{*}$. In practice, the mixing factor $V_{\mathrm{inj}}{ }^{*}$ is varied between 0 (Dirac-type tracer injection in the well $\delta_{\mathrm{w}}$ by defining a nonzero initial tracer concentration $C_{\mathrm{w}, 0}$ in the well) and 10 (i.e., a volume of traced water 10 times higher than the volume of water in the well). Because of the purely radially converging flow conditions considered in this

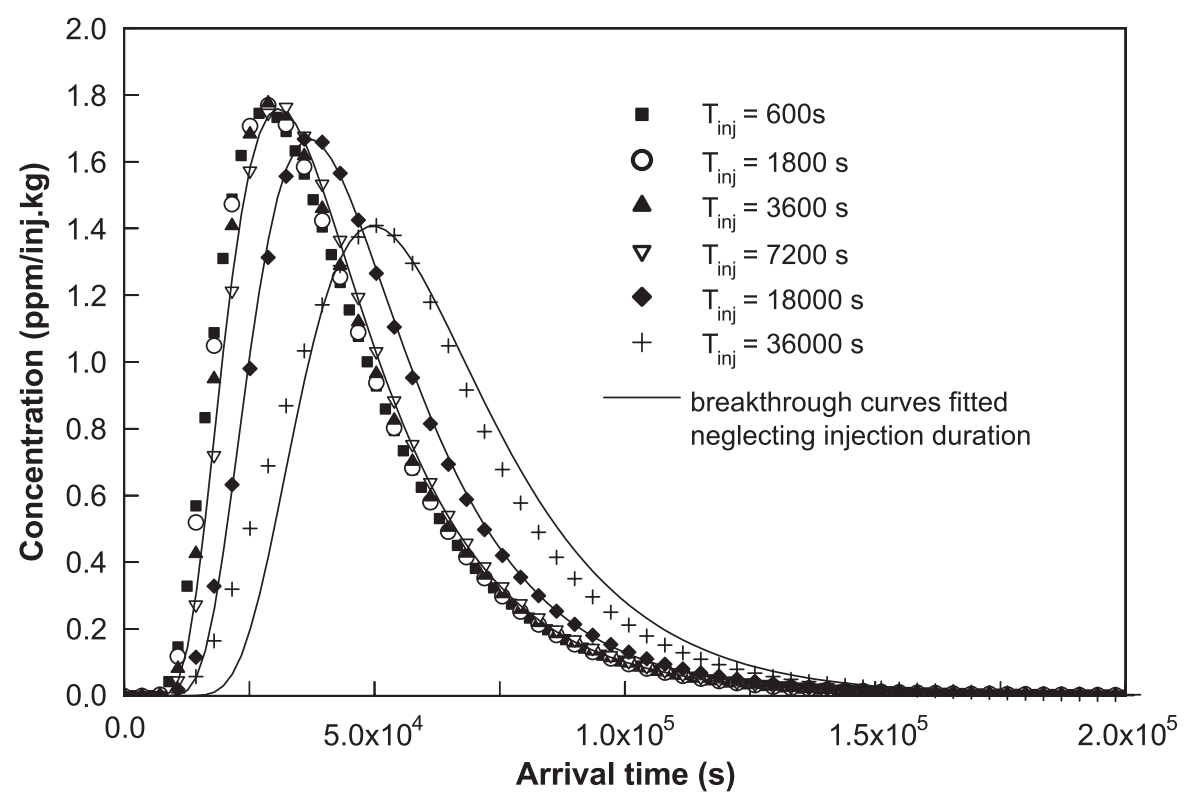

Figure 4. Field breakthrough curves generated using different injection durations (symbols) compared to breakthrough curves fitted neglecting the influence of injection duration (lines). 
synthetic example, Darcy velocities close to the injection well are prescribed by the pumping rate at the central well. In order to keep constant ground water flow and transport conditions from one simulation to the other, the distortion coefficient $\alpha_{\mathrm{w}}$ is "artificially" used to vary the transit flow rate across the screens. The coefficient $\alpha_{\mathrm{w}}$ is varied between 0.03 and 3 . Figure 5 shows the generated

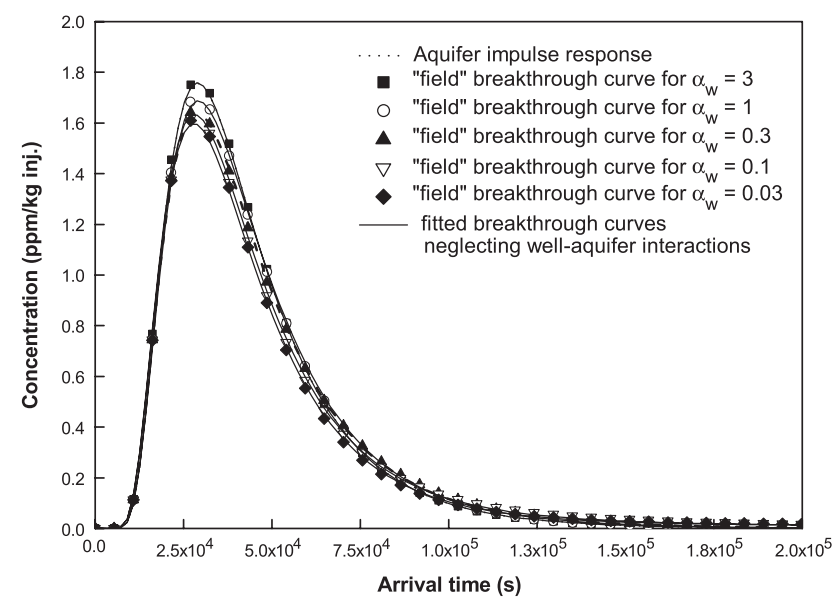

(a) $\mathrm{V}_{\text {inj }}{ }^{*}=10$

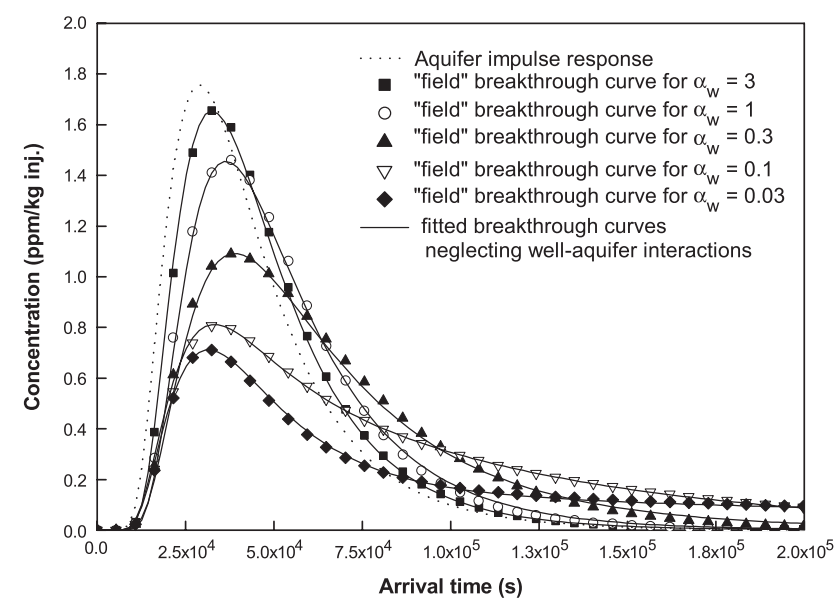

(c) $\mathrm{V}_{\text {inj }}{ }^{*}=1$

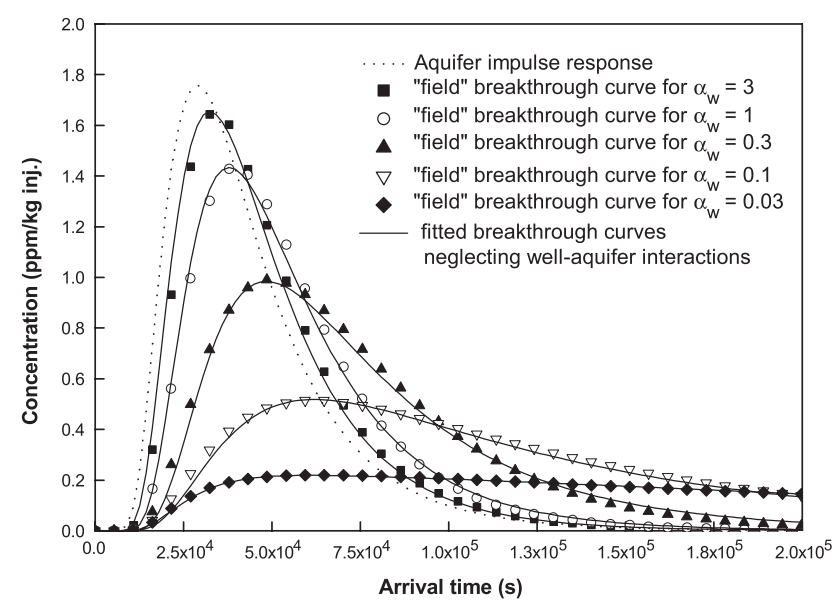

(e) $\mathrm{V}_{\text {inj }}{ }^{*}=0.1$ breakthrough curves (symbols) grouped together by constant mixing factors. For comparison, the aquifer response to a step-like tracer injection in the aquifer (using a classical source term of $2700 \mathrm{~s}$ ) is also presented. As expected, the mixing factor has a tremendous effect on the field breakthrough curves. For smaller values of the mixing factor, thus for small volumes of tracer fluid compared to

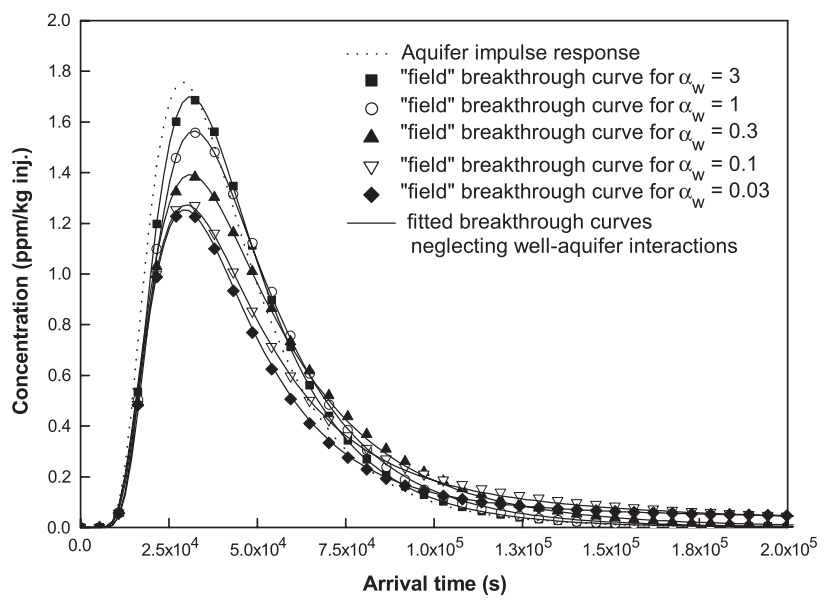

(b) $\mathrm{V}_{\mathrm{inj}}^{*}=3$

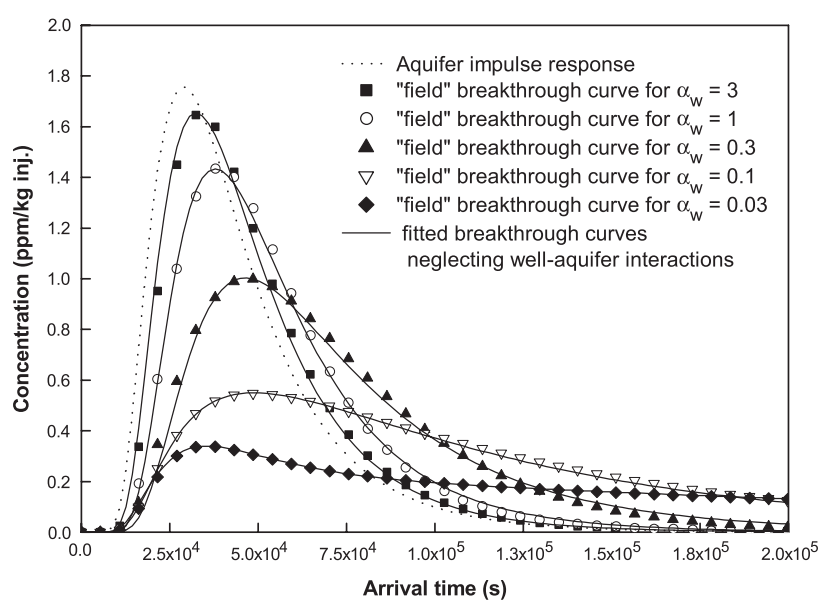

(d) $\mathrm{V}_{\text {inj }}{ }^{*}=0.3$

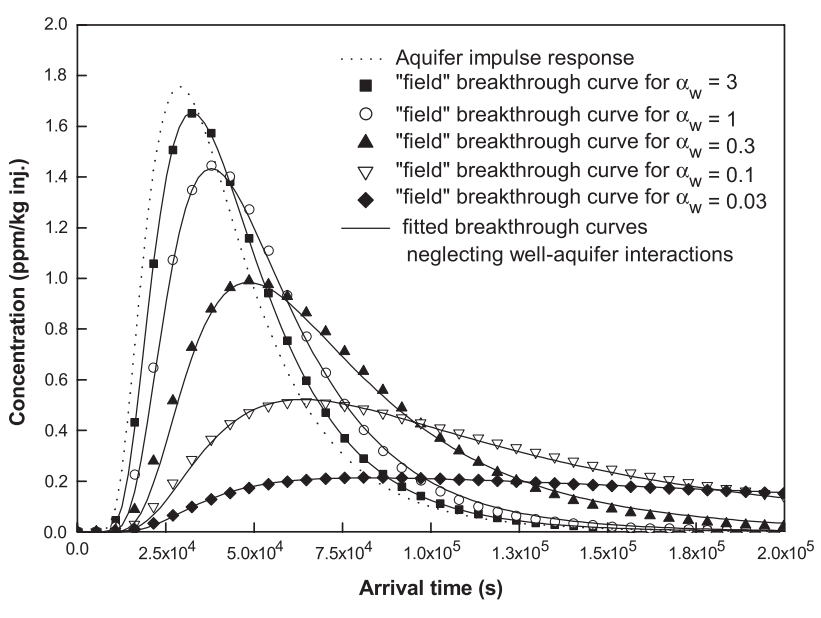

(f) $\mathrm{V}_{\text {inj }}{ }^{*}=0.0\left(\delta_{\mathrm{pz}}\right)$

Figure 5. Field breakthrough curves generated using the injection model (symbols) compared to breakthrough curves fitted neglecting the influence of injection conditions (lines). 
the volume of water in the injection well, the injection conditions have a much greater potential influence on the results. For a given mixing factor, it appears that as the transit flow rate decreases, the breakthrough curve exhibits greater concentration attenuation and tailing.

It can also be shown that breakthrough curves generated with the same distortion coefficient cross at an intersection point $\left(t_{\mathrm{M}}, C_{\mathrm{M}}\right)$, the location of which depends on the transit flow rate. This is illustrated in Figure 6. The intersection point corresponds to the maximum concentration of the breakthrough curve resulting from a Diractype tracer injection in the well, $\delta_{\mathrm{w}}(t)$. A progressive transition is observed between the aquifer impulse response $F_{\text {aq }}(t)$, corresponding to a Dirac-type tracer injection in the aquifer, $\delta_{\mathrm{aq}}(t)$, and the breakthrough curve denoted $F_{\text {aq,w }}(t)$, corresponding to a Dirac-type tracer injection in the well, $\delta_{\mathrm{w}}(t)$. This property is demonstrated in Appendix A.

As for evaluating the influence of the injection duration, calibration of apparent hydrodispersive parameters is performed by fitting computed breakthrough curves to field breakthrough curves. The computed breakthrough curves are simulated by neglecting well-aquifer interactions, thus modeling the injection with a source term (step function of $2700 \mathrm{~s}$ ) directly applied to the aquifer medium. In fact, this is similar to short-circuiting the injection well by considering its volume arbitrarily small ( $V_{w} \rightarrow 0$ thus $V_{\text {inj }}^{*} \rightarrow \infty$ ). The calibration procedure is as follows: breakthrough curves are adjusted by a trial-anderror procedure, using a minimum of two fitting parameters, i.e., the effective porosity $\theta_{\mathrm{m}}(-)$ and the longitudinal dispersivity $\alpha_{\mathrm{L}}(\mathrm{m})$. For many breakthrough curves, it is impossible to achieve a satisfactory fit using the advection-dispersion model. These breakthrough curves are characterized by low concentration peaks, strong asymmetry, and tailing. In the field, this kind of breakthrough curve is frequently observed in geological formations characterized by the presence of an important quantity of "immobile" water located in small pores (such as fissured chalk), in aggregates (macroporous soils), or in less pervious layers such as clay lenses in heterogeneous alluvial gravel deposits (Gerke and van Genuchten 1993; Brouyère 2001). Where the immobile water is in contact with the "mobile" water, a bidirectional transfer of solute is possible: first a transfer of solute from the mobile to the immobile water, explaining the concentration attenuation observed; second a release of the solute from the immobile water to the mobile water, explaining the tailing observed. These effects are often modeled using a dualporosity concept representing the exchange of solute between mobile and immobile water by a first-order transfer equation (e.g., Coats and Smith 1964; van Genuchten and Wierenga 1976; Brouyère et al. 2000). The dual-porosity model introduces two further parameters in the calibration process: the dual porosity $\theta_{\text {im }}$ (no units) and a first-order transfer coefficient $\alpha\left(\mathrm{T}^{-1}\right)$. There is a strong similarity between this physical process and the trapping of tracer in the wellbore. Here, the immobile water is located in the wellbore and the transfer of solute between mobile and immobile water is provided by the transit flow rate crossing the well screens. Due to this similarity, and because one could imagine that the experimenter performs the tracer test in order to identify hydrodispersive processes affecting the migration of solutes in the underground, for those breakthrough curves for which a satisfactory fit could not be achieved using the classical advection-dispersion model, the dual-porosity model was considered. In these cases, the best fit was achieved by calibrating apparent dual porosity $\theta_{\text {im }}(-)$ and first-order transfer coefficient $\alpha\left(\mathrm{T}^{-1}\right)$ parameters. Figure 5 shows the comparison of the fitted breakthrough curves (lines) with the field breakthrough curves (symbols). The evolution of each calibrated hydrodispersive parameter with respect to the two well-aquifer interaction parameters $\left(\alpha_{\mathrm{w}}\right.$ and $V_{\mathrm{inj}}{ }^{*}$ ) is presented in Figure 7.

These results clearly illustrate that well-aquifer interactions, if not well controlled and modeled, can lead to severe misinterpretation when fitting the breakthrough curves. Actual hydrodispersive parameters are poorly assessed by the calibration. Generally, effective porosity and longitudinal dispersivity are overestimated. Furthermore, the identification of hydrodispersive processes can

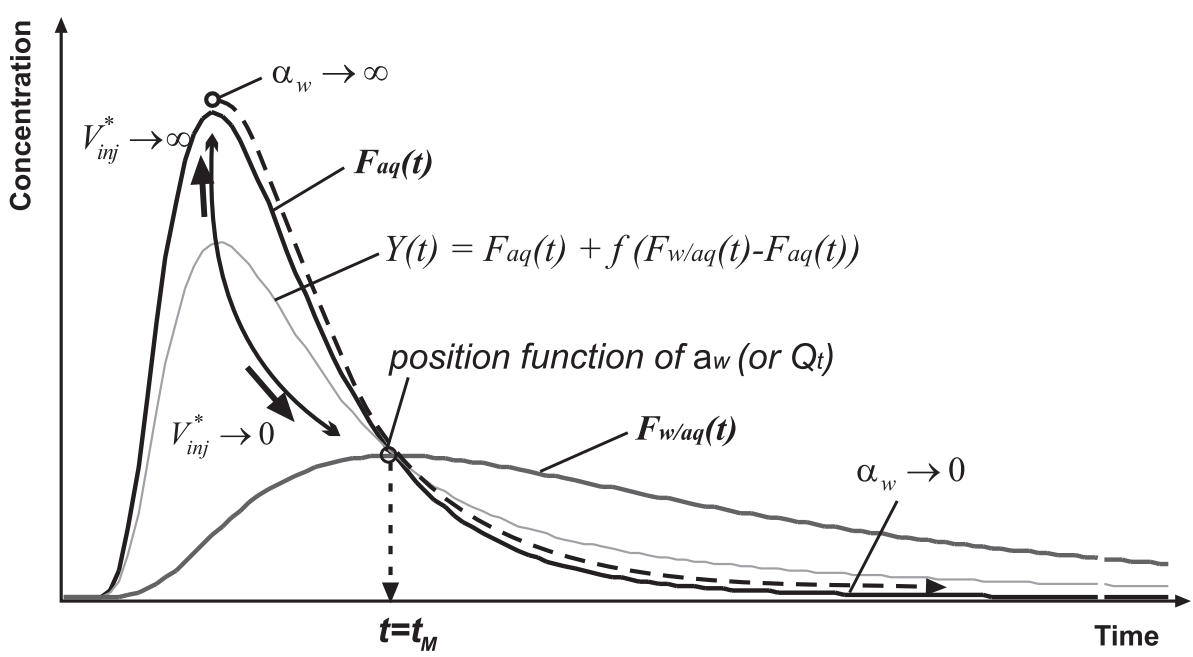

Figure 6. Evolution of the breakthrough curve for a constant distortion coefficient and variable mixing factors. 
Effective porosity (-)

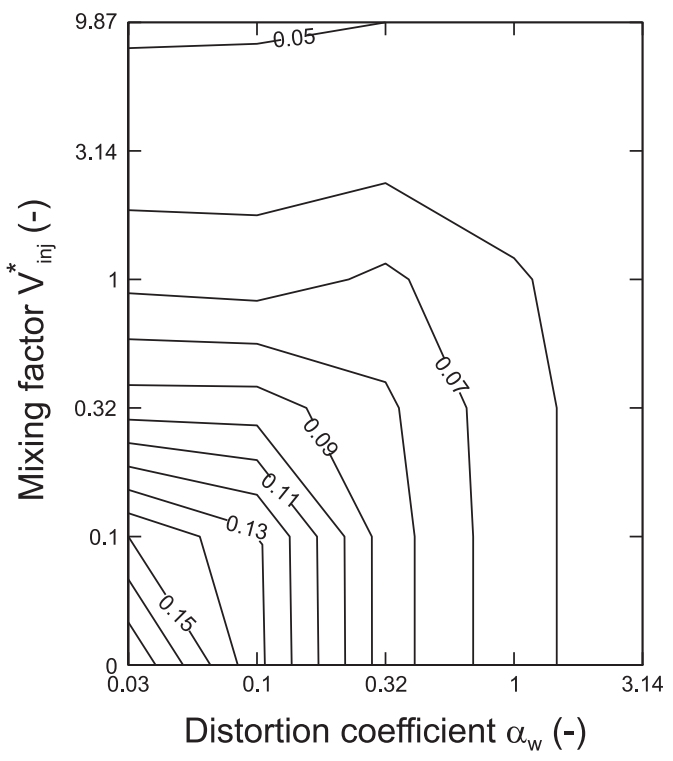

Transfer coefficient $\left(\mathbf{s}^{-1}\right)$

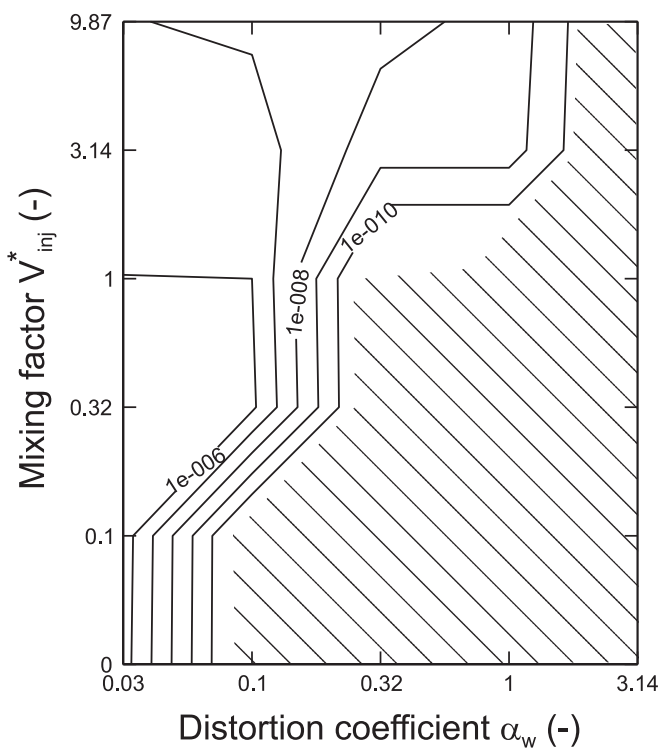

Longitudinal dispersivity (m)
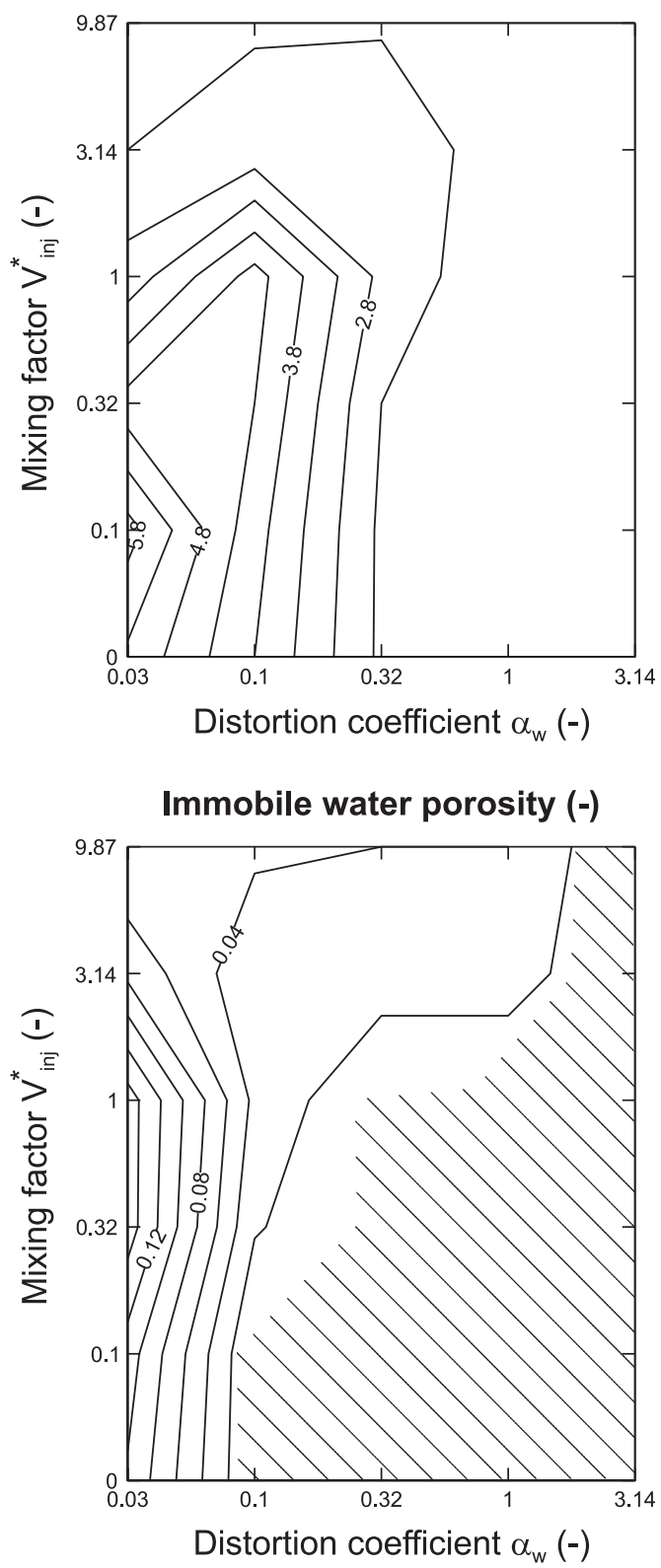

Figure 7. Evolution of each fitted hydrodispersive parameter according to the two parameters describing well-aquifer interactions (the hatched area corresponds to cases for which the dual-porosity concept was not necessary to fit the breakthrough curves).

also be biased. In the presented synthetic example, a majority of breakthrough curves could not be fitted with sufficient accuracy without considering dual-porosity effects, which, in this case, actually do not affect the field breakthrough curves.

\section{Conclusions and Guidelines}

Numerical experiments performed in this research clearly highlight the possible influence of experimental conditions associated with tracer injection on results and interpretation of field tracer tests. It is observed when the tracer input function in the aquifer is not instantaneous, in other words, it cannot be considered as very short compared to the mean residence time of the tracer in the aquifer. This is more likely to occur when the advective travel time between the injection well and the observation well is short.

Neglecting the injection duration can lead to significant discrepancy between the measured breakthrough curve and the aquifer impulse response. However, this is not a problem since the injection duration is fully under control by the experimenter, and it is straightforward to take into account when modeling the tracer experiment.

For a given experimental configuration, well-aquifer interactions can have more influence than injection duration on tracer test results and interpretation. Most often, experimental conditions are often not so ideal in the field. Tracer injections have to be performed in existing piezometers and wells. Because these wells are not necessarily drilled for the purpose of the experiment, they are usually not perfectly adapted: large volume of water in 
the wellbore, long screens, and continuous gravel packs that make it impossible to use a packer, etc. Moreover the wells can sometimes be deteriorated (clogged with mud). Experimenters should thus give great care to the possibility that tracer trapping in the injection wellbore actually occurs.

The analysis goes further by showing what kind of mistake the experimenter and the modeler are prone to. If not controlled, tracer injection can lead to erroneous quantification of hydrodispersive parameters (i.e., overestimation of the effective porosity and longitudinal dispersivity) and, more fundamentally, to erroneous identification of hydrodispersive processes (i.e., the migration of solutes in the aquifer seems artificially affected by a strong physical retardation). This could lead to underestimation of the natural attenuation capacity of the tested aquifer medium, with major consequences, for example, in the dimensioning of pollution remediation techniques or in the definition of protection zones.

Guidelines can be proposed in order to prevent misinterpretation of tracer test results in relation with injection conditions.

An experimental setup that minimizes the influence of injection conditions on the results must be adopted by ensuring that the tracer is instantaneously and completely injected into the aquifer. This can be performed using a packer system that isolates the level at which the tracer should be injected and reduces the mixing volume of water in the packer.

Very often, due to the existence of a gravel pack around the well, a packer system cannot be used for isolating the portion of the well where the tracer injection is desired. In that case, a very large fluid tracer volume (compared to the volume of water in the injection well) must be used to reduce to a minimum the quantity of tracer trapped in the well at the end of injection. Based on the results presented here, it appears that the volume of tracer fluid must at least be equal to 10 times the volume of water in the injection well.

In many practical situations, the adequate quantity of water is not available (e.g., the injection well is located far away from any water facility or the volume of water in the wellbore is so large that the adequate quantity of water cannot be handled). The alternative solution consists in monitoring the concentration evolution at the injection well and to model it explicitly afterward. A water circulation has to be performed in the injection wellbore to homogenize the tracer concentration and to obtain samples at the injection point. It requires also the implementation of the modeling approach proposed by Brouyère (2003) in existing ground water flow and transport simulators. In addition, the concentration evolution at the injection well can provide interesting information on ground water flow conditions prevailing near that point (Brouyère 2001).

Using analytical solutions assuming that the tracer is diluted into an infinitesimal volume of water instantaneously and perfectly mixed with water present in the injection wellbore (Dirac-type tracer injection in the wellbore $\delta_{\mathrm{w}}$ ), several authors have shown that injection and withdrawal wells characterized by large mixing factors are likely to present breakthrough curves that depart from the aquifer impulse response. Here, these results are generalized for any kind of tracer input function in the aquifer, including finite volume of tracer fluid. Unfortunately, a direct comparison between existing approaches and the new injection model is not feasible because there are several differences in mathematical assumptions that would make the comparison unclear. However, using the new injection model with a Dirac-type tracer injection in the well $\delta_{\mathrm{w}}$ produces breakthrough curves such as those presented in Figure 5f. For a given distortion coefficient, these breakthrough curves are always more attenuated and delayed compared to any breakthrough curve obtained with a finite-volume tracer injection (Figure 6). This means that existing analytical solutions overestimate the influence of tracer trapping in the wellbore when the tracer fluid volume is finite. If modelers are not aware of that, they will underestimate the effective porosity and longitudinal dispersivity to obtain a satisfactory fit of the measured breakthrough curve. This confirms that the new approach proposed by Brouyère (2003) is an improvement over previous existing modeling concepts for modeling tracer injection and interpretation of tracer experiments.

\section{Appendix A: Demonstration of the Existence of an Intersection Point for All Breakthrough Curves Generated Using a Constant Distortion Coefficient and Variable Mixing Factors}

When the injection duration is negligible, the tracer input function in the aquifer can be expressed as a linear combination between a Dirac function directly applied to the aquifer $\delta_{\mathrm{aq}}(t)$ and the injection well impulse response $F_{\mathrm{w}}(t)$ :

$$
X_{\mathrm{aq}}(t)=f F_{\mathrm{w}}(t)+(1-f) \delta_{\mathrm{aq}}(t)=\delta_{\mathrm{aq}}(t)+f\left(F_{\mathrm{w}}(t)-\delta_{\mathrm{aq}}(t)\right)
$$

A value of $f=0$ corresponds to a complete bypass of the injection well $\left(V_{\mathrm{inj}}^{*} \rightarrow \infty\right)$, i.e., to a "pure" Dirac function applied to the aquifer. In this case, the breakthrough curve is equal to the aquifer impulse response:

$$
Y(t)=F_{\mathrm{aq}}(t) * \delta_{\mathrm{aq}}(t)=F_{\mathrm{aq}}(t)
$$

A value of $f=1$ corresponds to a Dirac-type tracer injection in the well $\left(V_{\mathrm{inj}}^{*} \rightarrow 0\right)$. In this case, the breakthrough curve is the impulse response of the combined wellaquifer system:

$$
Y(t)=F_{\mathrm{aq}}(t) * F_{\mathrm{w}}(t)=F_{\mathrm{w} / \mathrm{aq}}(t)
$$

For a given injection profile $X_{\mathrm{aq}}(t)$ in the aquifer, one can write:

$$
\begin{aligned}
& Y(t)= F_{\mathrm{aq}}(t) * X_{\mathrm{aq}}(t)=F_{\mathrm{aq}}(t) *\left(\delta_{\mathrm{aq}}(t)\right. \\
&\left.+f\left(F_{\mathrm{w}}(t)-\delta_{\mathrm{aq}}(t)\right)\right) \\
& Y(t)=F_{\mathrm{aq}}(t)+f\left(F_{\mathrm{w} / \mathrm{aq}}(t)-F_{\mathrm{aq}}(t)\right)
\end{aligned}
$$




$$
\begin{aligned}
& \text { For } t=t_{\mathrm{M}}, F_{\mathrm{w} / \mathrm{aq}}\left(t_{\mathrm{M}}\right)=F_{\mathrm{aq}}\left(t_{\mathrm{M}}\right) \text { and, } \\
& \quad Y\left(t_{\mathrm{M}}\right)=F_{\mathrm{aq}}\left(t_{\mathrm{M}}\right)=F_{w / \mathrm{aq}}\left(t_{\mathrm{M}}\right)=C_{\mathrm{M}}
\end{aligned}
$$

This demonstrates that each breakthrough curve must pass through the same point. The relative position of the actual breakthrough curve, between the aquifer impulse response $F_{\text {aq }}(t)$ and the combined well-aquifer impulse response $F_{\text {w/aq }}(t)$, thus the factor $f$, is a function of the mixing factor $V_{\text {inj }}^{*}$. As $V_{\text {inj }}^{*}$ increases, the breakthrough curve becomes closer to the aquifer impulse response. Meanwhile, the position of the intersection point $\left(t_{\mathrm{M}}, C_{\mathrm{M}}\right)$ is related to the intensity of the transit flow rate during injection. As the transit flow rate decreases, the matching point is more delayed and the breakthrough curve is more likely to be affected by well-aquifer interactions.

\section{Acknowledgments}

The authors would like to thank Claire Tiedeman (USGS), Robin M. Field, and Malcolm Field (USEPA) for useful comments on the manuscript and for the careful editing of the English redaction, the three reviewers, Allen Moench, Paul Hsieh, Tim Scheibe, and the Associate Editor whose comments and suggestions helped to improve the quality of the manuscript. The Ph.D. research of S. Brouyère was supported by a 4-year grant provided by the Funds for Scientific Research of Belgium.

\section{References}

Bidaux, P., and C.-F. Tsang. 1991. Fluid flow patterns around a well bore or an underground drift with complex skin effects. Water Resources Research 27, no. 11: 2993-3008.

Brouyère, S. 2003. Modeling tracer injection and well-aquifer interactions: A new mathematical and numerical approach. Water Resources Research 39, no. 3: 1070.

Brouyère, S. 2001. Study and modeling of transport and capturing of solutes in variably saturated media (in French). Ph.D. diss., Faculty of Applied Sciences, University of Liège, Liège, Belgium.

Brouyère, S., A. Dassargues, R. Therrien, and E.A. Sudicky. 2000. Modelling of dual porosity media: Comparison of different techniques and evaluation on the impact on plume transport simulations. In Post Published Proceedings of MODELCARE'99, IAHS Publication no. 265, ed.
F. Stauffer, W. Kinzelbach, K. Kovar, and E. Hoehn, 22-27. Wallingford, Oxfordshire, UK: IAHS Press.

Carabin, G., and A. Dassargues. 1999. Modeling groundwater with ocean and river interaction. Water Resources Research 35, no. 8: 2347-2358.

Chen, J.-S., C.-W. Liu, C.S. Chen, and C.-M. Liao. 2003. Effect of well bore mixing volume on non-axisymmetrical transport in a convergent radial tracer test. Journal of Hydrology 277, no. 1-2: 61-73.

Coats, K.H., and B.D. Smith. 1964. Dead-end pore volume and dispersion in porous media. Society of Petroleum Engineering Journal 4, 73-84.

Drost, W., D. Klotz, K. Arnd, M. Heribert, F. Neumaier, and W. Rauert. 1968. Point dilution methods of investigating ground water flow by means of radioisotopes. Water Resources Research 4, no. 1: 125-146.

Gerke, H.H., and M.Th. van Genuchten. 1993. A dual-porosity model for simulating the preferential movement of water and solutes in structured porous media. Water Resources Research 29, no. 2: 305-319.

Guvanasen, V., and V.M. Guvanasen. 1987. An approximate semianalytical solution for tracer injection tests in a confined aquifer with a radially converging flow field and a finite volume of tracer and chase fluid. Water Resources Research 23, no. 8: 1607-1619.

Hall, S.H. 1996. Practical single-well tracer methods for aquifer testing. In Tenth National Outdoor Action Conference and Exposition, 11. Columbus, Ohio: National Groundwater Association. Accessed at www.sibak.com/Library/0006.htm

Havely, E., H. Moser, O. Zellhofer, and A. Zuber. 1967. Borehole dilution techniques: A critical review. In Isotopes in Hydrology, 531-564. Vienna, Austria: IAEA.

Moench, A.F. 1989. Convergent radial dispersion: A Laplace transform solution for aquifer tracer testing. Water Resources Research 25, no. 3:, 439-447. (Correction in Water Resources Research 32, no. 5 (1996): 1457.)

Novakowski, K. 1992a. An evaluation of boundary conditions for one-dimensional solute transport, 1. Mathematical development. Water Resources Research 28, no. 9: 2399-2410.

Novakowski, K. 1992b. An evaluation of boundary conditions for one-dimensional solute transport, 2. Column experiments. Water Resources Research 28, no. 9: 2411-2423.

van Genuchten, M. Th., and P.J. Wierenga. 1976. Mass transfer studies in sorbing porous media: I. Analytical solutions. Soil Science Society of America Journal 40, 473-480.

Welty, C., and L.W. Gelhar. 1994. Evaluation of longitudinal dispersivity from nonuniform flow tracer tests. Journal of Hydrology 153, no. 1-4: 71-102.

Zlotnik, V.A., and J.D. Logan. 1996. Boundary conditions for convergent radial tracer tests and effect of well bore mixing volume. Water Resources Research 32, no. 7: 2323-2328. 